\title{
Long-Term Clinical Outcome of First Recurrence Skull Base Meningiomas
}

\author{
Yuki Kuranari ${ }^{1}$, Ryota Tamura ${ }^{1}$, Noboru Tsuda ${ }^{2}$, Kenzo Kosugi ${ }^{1}{ }^{\circledR}$, Yukina Morimoto ${ }^{1}$, \\ Kazunari Yoshida ${ }^{1}$ and Masahiro Toda ${ }^{1, *}$ \\ 1 Department of Neurosurgery, Keio University School of Medicine, 35 Shinanomachi, Shinjuku-ku, \\ Tokyo 160-8582, Japan; yuki_kuranari@keio.jp (Y.K.); moltobello-r-610@hotmail.co.jp (R.T.); \\ kensan03977@yahoo.co.jp (K.K.); yukinaxnashiko@yahoo.co.jp (Y.M.); kazrmky@keio.jp (K.Y.) \\ 2 Department of Pathology, Keio University School of Medicine, 35 Shinanomachi, Shinjuku-ku, \\ Tokyo 160-8582, Japan; akaishidake@gmail.com \\ * Correspondence: todam@keio.jp; Tel.: +81-3-3353-1211
}

Received: 19 November 2019; Accepted: 29 December 2019; Published: 31 December 2019

\begin{abstract}
Skull base meningiomas (SBMs) are considered to be less aggressive and have a slower growth rate than non-SBMs. However, SBMs often develop local recurrences after surgical resection. Gross total removal is difficult because SBMs are deep-seated tumors and involve critical neurovascular structures. The treatment strategy for recurrent SBMs remains controversial. The present study aimed to evaluate the long-term clinical course and prognostic factors associated with shorter progression-free survival (PFS) of recurrent SBMs. This retrospective study included 85 recurrent SBMs from 65 patients who underwent surgery from January 2005 to September 2018. Overall survival (OS) and PFS were evaluated, and the associations among shorter PFS and age, sex, tumor size, lesions, World Health Organization (WHO) grading, removal rate, and time since prior surgery were analyzed. The median follow-up period for PFS was 68 months. The 2-, 5-, and 10-year PFS rates were $68.0 \%, 52.8 \%$, and $22.7 \%$, respectively. WHO grade II or III, multiple lesions, and tumor size were significantly associated with shorter PFS $(p<0.0001, p=0.030$, and $p=0.173$, respectively). Although, radiotherapy did not improve PFS and OS for overall patients, PFS of the patients with subtotal and partial removal for WHO grade II SBMs was significantly improved by the radiotherapy. Multivariate analysis identified WHO grade II or III and multiple lesions as independent prognostic factors for shorter PFS ( $p<0.0001$ and $p=0.040$, respectively). It is essential to estimate the risks associated with shorter PFS for patients with recurrent SBMs to aid in the development of appropriate postoperative strategies.
\end{abstract}

Keywords: skull base meningioma; recurrence; atypical; anaplastic; adjuvant radiotherapy

\section{Introduction}

The growth rate of meningiomas is known to differ depending on their location [1]. Skull base meningiomas (SBMs) typically grow slower and are more likely to show a lower MIB-1 index than non-SBMs [2-4]. The WHO grade I subpopulation comprises a vast majority of SBMs $[1,2,4,5]$. Recurrent SBMs have a relatively long overall survival (OS) [6]. However, compared with non-SBMs, SBMs often develop local recurrences after surgical resection $[7,8]$, which leads to the gradual deterioration of patients' quality of life. Gross total removal (GTR) is difficult because SBMs are deep-seated, and surrounded by critical vascular structures and cranial nerves [1,7,9-11].

Although, other treatment strategies, including chemo-radiotherapy, have been previously used for patients with recurrent and progressive meningiomas [12-14], chemotherapies, including sunitinib [13], bevacizumab [14], and everolimus [14], have shown limited efficacy. Recently, several studies 
have demonstrated the efficacy of adjuvant radiotherapy for high-grade meningiomas [15-17] and SBMs $[18,19]$ after initial surgical resection. Various forms of adjuvant radiotherapy, including fractionated radiotherapy and stereotactic radiosurgery, have been found to improve local control $[16,17,19]$. However, the efficacy of adjuvant radiotherapy for the recurrent stage of SBMs remains unclear $[16,17]$. Few studies have specifically investigated prognostic factors of recurrent SBMs. Therefore, the treatment strategy for recurrent SBMs remains controversial.

The present study aimed to evaluate the long-term clinical courses and prognostic factors associated with shorter progression-free survival (PFS) and OS of recurrent SBMs for the development of appropriate treatment strategies for recurrent SBMs.

\section{Materials and Methods}

This study was approved by the Institutional Review Board of Keio University (Reference number: 20,050,002), and informed consent was obtained from all patients.

\subsection{Study Population}

A total of 783 cases of patients who were surgically treated with meningiomas were screened at our hospital from January 2005 to September 2018. Among those, this retrospective study included 85 cases of recurrent SBMs from 65 patients (Figure 1). SBMs were defined, as described previously [20].

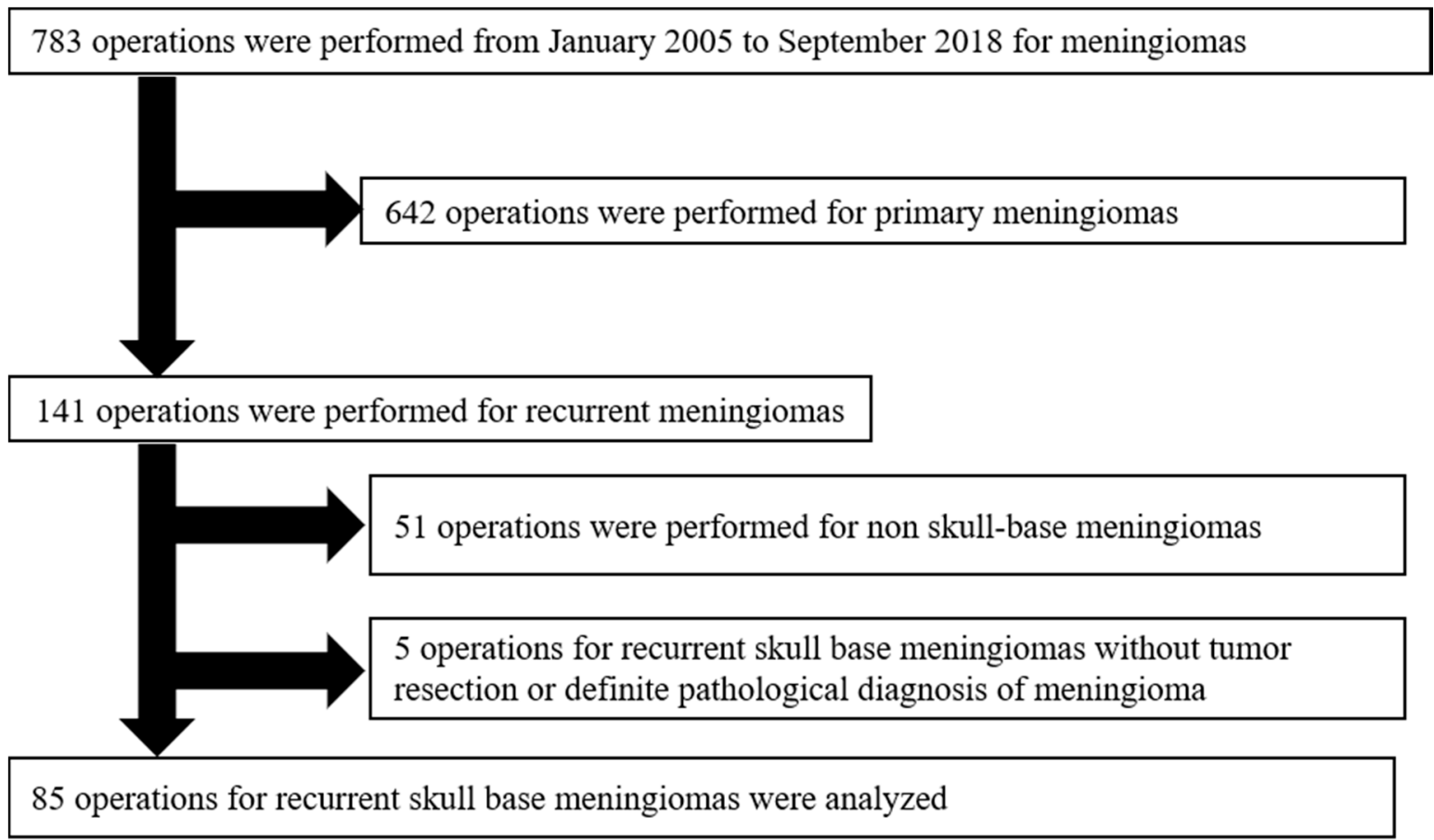

Figure 1. Patient selection in the study. A total of 783 surgically treated cases with meningiomas were screened. Among those, this retrospective study included 85 recurrent SBMs from 65 patients. The exclusion criteria were as follows: (1) Patients who underwent an optic nerve or orbital decompressive operation without tumor resection $(n=4)$, and (2) patients with a small surgical specimen, for which it was difficult to make a definitive diagnosis $(n=1)$.

The exclusion criteria of this study were as follows: (1) Patients who underwent an optic nerve or orbital decompressive operation without tumor resection $(n=4)$; and (2) patients with a small surgical specimen which made a definitive diagnosis difficult $(n=1)$.

Surgical data were retrieved from operative reports, and information on tumor histology was obtained from pathology reports. The data regarding the length of hospital stay and postoperative complications were also obtained. All other information was collected from hospital paper and 
electronic medical charts. Gadolinium (Gd)-enhanced T1-weighted magnetic resonance imaging (MRI) was used to evaluate tumor size and location. Tumor recurrence was defined as follows: (1) For patients with complete resection, the appearance of new lesions at the prior surgical site; (2) for patients with incomplete resection, residual tumor growth ( $>2 \mathrm{~mm} / \mathrm{year})$; and (3) appearance of the disseminated lesion.

Tumor size was analyzed using the longest diameter, as described previously [21,22]. For multiple meningiomas, tumor size was defined as the longest diameter of the largest one [23]. The removal rate was validated using postoperative routine head computed tomography at 7 days after the operation. Routine postoperative MRI was performed every 6-12 months.

The Simpson grading scale was also used to evaluate the removal rate [24]. The removal rate was categorized as GTR (Simpson grade I and II), subtotal removal (STR) (Simpson grade III), and partial removal (PR) (Simpson grade IV), as previously described [1,10]. In patients with a planned two-stage surgery, the total removal rate was used for the analysis.

PFS was defined as the time that elapsed between treatment initiation and tumor progression. OS was defined as the time from treatment initiation to death. Patients still alive at the last visit were censored as the date of the last follow-up.

\subsection{Statistical Analysis}

Students' $t$-test was used to compare the length of hospital stay and complication rate among reoperations. PFS and OS were estimated using the Kaplan-Meier method and the log-rank test. We performed univariate analysis with Cox regression models to investigate the poor prognostic factors of recurrent SBMs after surgical resection. Variables with a $p$-value of $<0.2$ were included in a subsequent multivariate analysis. A $p$-value of $<0.05$ was considered to be statistically significant. Analyses were performed using JMP (version 14.0, SAS Institute Inc., Cary, North Carolina, NC, USA).

\section{Results}

\subsection{Patient Characteristics}

The characteristics of the 65 patients with recurrent SBMs (male: 12, female: 53) have been summarized in Table 1. The median follow-up period was 68 months (range, 0-130 months). The median age at reoperation was 59 years (range, 28-82 years). Among the 65 patients, WHO grade I meningiomas were observed in 52 patients, grade II meningiomas in 12, and grade III meningioma in 1 . The median size of the recurrent tumor was $37 \mathrm{~mm}$ (range, $4-70 \mathrm{~mm}$ ). Multiple meningiomas were observed in 10 patients. Most of the recurrent SBMs were located in the middle or posterior cranial fossa (middle: 28 , posterior: 27). Only 1 patient showed meningiomatosis with extensive dural thickness at the time of recurrence. 
Table 1. Patient characteristics $(N=65)$.

\begin{tabular}{|c|c|}
\hline Parameter & Number (\%) \\
\hline \multicolumn{2}{|l|}{ Sex } \\
\hline Male & $12(17.4)$ \\
\hline Female & $53(82.6)$ \\
\hline \multicolumn{2}{|l|}{ Time since prior surgery } \\
\hline$<10$ years & $48(73.8)$ \\
\hline$\geq 10$ years & $17(26.2)$ \\
\hline \multicolumn{2}{|l|}{ WHO grading } \\
\hline $\mathrm{I}$ & $52(80.0)$ \\
\hline II & $12(18.5)$ \\
\hline III & $1(1.5)$ \\
\hline Tumor size (mm) & $37(4-70)$ \\
\hline Diameter $\geq 60 \mathrm{~mm}$ & $11(16.9)$ \\
\hline Diameter $\geq 30 \mathrm{~mm},<60 \mathrm{~mm}$ & $32(49.2)$ \\
\hline Diameter $<30 \mathrm{~mm}$ & $22(33.9)$ \\
\hline \multicolumn{2}{|l|}{ Lesions } \\
\hline Multiple & $10(15.4)$ \\
\hline Single & $55(84.6)$ \\
\hline \multicolumn{2}{|l|}{ Location } \\
\hline Anterior cranial fossa & $9(13.9)$ \\
\hline Olfactory groove & $2(3.1)$ \\
\hline Tuberculum sellae & $7(10.8)$ \\
\hline Middle cranial fossa & $28(43.1)$ \\
\hline Sphenoid wing & $4(6.2)$ \\
\hline Anterior clinoid process & $5(7.7)$ \\
\hline Cavernous sinus & $7(10.8)$ \\
\hline Floor & $7(10.8)$ \\
\hline Optic canal and orbit & $3(4.6)$ \\
\hline Meckel's cave & $1(1.5)$ \\
\hline Spheno-orbital & $1(1.5)$ \\
\hline Posterior cranial fossa & $27(41.5)$ \\
\hline Petroclival & $9(13.8)$ \\
\hline Spheno-petroclival & $2(3.1)$ \\
\hline Petrosal bone & $7(10.8)$ \\
\hline Jugular foramen & $1(1.5)$ \\
\hline Tentorial & $5(7.7)$ \\
\hline Foramen magnum & $3(4.6)$ \\
\hline Meningiomatosis & $1(1.5)$ \\
\hline
\end{tabular}

WHO, World Health Organization.

\subsection{Operation Characteristics}

Table 2 summarizes the operation characteristics at the time of recurrence; 85 operations (first reoperation: 53, second reoperation: 23, third reoperation: 9) were analyzed. Seventy-two craniotomies, 12 endoscopic endonasal approaches, and one combined approach (craniotomy + endoscopic endonasal approach) were performed. Four operations were planned two-stage surgeries. Surgical approaches for each craniotomy are summarized in Table 3. The frontotemporal approach and anterior transpetrosal approach [25] were frequently used. GTR (Simpson grade I and II), STR (Simpson grade III), and PR (Simpson grade IV) were achieved in 27, 33, and 21 operations, respectively (Table 3). Forty-nine operations were performed after both symptomatic and radiographical progression and 32 operations after radiological progression alone. Visual impairment was observed before 20 reoperations and proptosis and facial numbness before 7 reoperations. Overall, $43 \mathrm{WHO}$ grade I meningiomas and 10 grade II meningiomas were observed in the first reoperation; 14 grade I, 8 grade II, and 1 grade III in the second reoperation; and 4 grade I and 5 grade II in the third reoperation. 
Table 2. Reoperation characteristics $(N=85)$.

\begin{tabular}{cc}
\hline Parameter & Number (\%) \\
\hline Operation & 85 \\
First reoperation & $53(63.3)$ \\
Second reoperation & $23(26.7)$ \\
Third reoperation & $9(10.0)$ \\
Two-staged surgery & $4(4.7)$ \\
Symptomatic & $49(60.5)$ \\
progression & $20(24.7)$ \\
Visual impairment & $7(8.6)$ \\
Proptosis & $7(8.6)$ \\
Facial numbness & $3(3.7)$ \\
Headache & $3(3.7)$ \\
Gait disturbance & $2(2.5)$ \\
Cognitive changes & $2(2.5)$ \\
Hearing disturbance & $5(6.2)$ \\
Other symptoms & $32(39.5)$ \\
Radiological & \\
progression &
\end{tabular}

Table 3. Detailed information of surgical approach and removal rate $(N=85)$.

\begin{tabular}{|c|c|c|c|c|}
\hline Variable & First Reope & Second Reope & Third Reope & Total \\
\hline Number of operations & 53 & 23 & 9 & 85 \\
\hline Craniotomy & 47 & 19 & 6 & 72 \\
\hline Frontotemporal approach & 14 & 8 & 4 & 26 \\
\hline Orbitozygomatic approach & 5 & 2 & 0 & 7 \\
\hline Anterior transpetrosal approach & 8 & 3 & 0 & 11 \\
\hline Combined transpetrosal approach & 6 & 2 & 0 & 8 \\
\hline Posterior transpetrosal approach & 1 & 0 & 0 & 1 \\
\hline Lateral suboccipital approach & 3 & 0 & 0 & 3 \\
\hline Transcondylar fossa approach & 3 & 1 & 0 & 4 \\
\hline Other approach & 7 & 3 & 2 & 12 \\
\hline Endonasal endoscopic surgery & 6 & 3 & 3 & 12 \\
\hline $\begin{array}{l}\text { Combined approach (Craniotomy+ } \\
\text { Endonasal endoscopic surgery) }\end{array}$ & 0 & 1 & 0 & 1 \\
\hline \# Removal rate & & & & 81 \\
\hline $\begin{array}{l}\text { Gross total removal } \\
\text { (Simpson grade I and II) }\end{array}$ & 21 & 5 & 1 & 27 \\
\hline $\begin{array}{r}\text { Subtotal removal } \\
\text { (Simpson grade III) }\end{array}$ & 19 & 11 & 3 & 33 \\
\hline $\begin{array}{c}\text { Partial removal } \\
\text { (Simpson grade IV) }\end{array}$ & 10 & 6 & 5 & 21 \\
\hline
\end{tabular}

Reope, reoperation. ${ }^{\#}$ In patients with planned two-stage surgery, the total removal rate was used for the analysis.

\subsection{Length of Hospital Stay and Postoperative Complications}

Length of hospital stay (days) and postoperative complications are summarized in Table 4. Length of hospital stay was 22.1, 19.6, and 45.9 days for each reoperation, respectively. Length of hospital stay at the third reoperation was significantly longer than that at the first or second reoperation ( $p=0.0059$ and $p=0.0066$, respectively).

Forty-eight complications were observed after all operations for 32 patients (Table 4). Of 53 patients who underwent first reoperation, 20 patients had complications. In the present study, new cranial nerve deficits and infections were the major complications for first recurrence SBMs. Eight out of 23 patients and 4 out of 9 patients had postoperative complications at the second and third reoperations, respectively. There were no differences in the complication rate among the reoperations $(p=0.2455$ and $p=0.5174$, respectively). 
Table 4. Length of hospital stay and complications for each reoperation $(N=85)$.

\begin{tabular}{ccccc}
\hline Variable & First Reope & Second Reope & Third Reope & Total \\
\hline $\begin{array}{c}\text { Number of operations } \\
\text { length of hospital stay (days) }\end{array}$ & 53 & 23 & 9 & 85 \\
Number of patients with & 22.1 & 19.6 & 45.9 & \\
complications & $20(35)$ & $8(9)$ & $4(4)$ & 48 \\
(Total number of complications) & & & & 17 \\
Complications & 35 & 9 & 4 & 3 \\
New cranial nerve deficits & 15 & 2 & 0 & 1 \\
CN II & 3 & 0 & 0 & 2 \\
CN III & 1 & 0 & 0 & 1 \\
CN IV & 2 & 0 & 0 & 3 \\
CN V & 1 & 0 & 0 & 6 \\
CN VI & 3 & 0 & 0 & 4 \\
CN VII & 5 & 2 & 0 & 1 \\
Other neurological deficits & 4 & 2 & 0 & 1 \\
Diabetes insipidus & 2 & 2 & 0 & 2 \\
Hemiparesis & 1 & 0 & 0 & 1 \\
Dysphagia & 1 & 0 & 0 & 3 \\
Postoperative hematoma & 1 & 1 & 0 & 1 \\
Cerebral infarction & 1 & 0 & 0 & 2 \\
Cerebral contusion & 0 & 1 & 0 & 2 \\
Cerebral edema & 1 & 2 & 1 & 9 \\
Vascular injuries & 0 & 0 & 0 & 4 \\
CSF leakage & 2 & 0 & 1 & 3 \\
Hydrocephalus & 1 & 0 & 1 & \\
Infection & 8 & 0 & 0 & \\
Meningitis & 4 & 0 & 1 & \\
Urinary tract infection & 1 & 0 & 1 & \\
Other infection & 3 & 0 & & \\
Other complications & 2 & 1 & & \\
\hline
\end{tabular}

Reope, reoperation; $\mathrm{CN}$, cranial nerve.

\subsection{Tumor Histology, Removal Rate, and Postoperative Radiotherapy of Each Reoperation}

Tumor histology, removal rate, and postoperative radiotherapy at each reoperation are summarized in Table 5. In our institution, patients underwent adjuvant radiotherapy, based on tumor WHO grade, location, and removal rate. Adjuvant radiotherapy was performed for the most patients with WHO grade II SBMs who could not achieve GTR. SRS/SRT and IMRT/3D CRT were used as the adjuvant radiotherapy. In contrast, in patients with WHO grade ISBMs, adjuvant radiotherapy was not routinely performed. However, 9 patients with progressive WHO grade I SBMs who could not achieve GTR received adjuvant radiotherapy. 
Table 5. Detailed information of tumor histology, removal rate and postoperative radiotherapy at each reoperation $(N=85)$.

\begin{tabular}{|c|c|c|c|c|c|}
\hline \multicolumn{2}{|c|}{ Variable } & First Reope & Second Reope & Third Reope & Total \\
\hline \multicolumn{2}{|l|}{ Number of operations } & 53 & 23 & 9 & 85 \\
\hline Tumor histology & ${ }^{\#}$ Removal rate & & & & \\
\hline \multirow{3}{*}{ WHO grade I } & GTR & 15 & 2 & 0 & 17 \\
\hline & STR & 16 & 7 & 0 & 23 \\
\hline & PR & 10 & 4 & 4 & 18 \\
\hline \multirow{3}{*}{ WHO grade II } & GTR & 6 & 3 & 1 & 10 \\
\hline & STR & 3 & 4 & 3 & 10 \\
\hline & PR & 0 & 1 & 1 & 2 \\
\hline WHO grade III & PR & 0 & 1 & 0 & 1 \\
\hline \multicolumn{2}{|l|}{ Adjuvant radiotherapy } & 9 & 6 & 2 & 17 \\
\hline \multicolumn{2}{|l|}{ SRS/SRT } & 8 & 3 & 2 & 13 \\
\hline \multicolumn{2}{|l|}{ IMRT/3D CRT } & 1 & 3 & 0 & 4 \\
\hline \multirow{2}{*}{ WHO grade I } & STR & 4 & 2 & 0 & 6 \\
\hline & PR & 2 & 0 & 1 & 3 \\
\hline \multirow{2}{*}{ WHO grade II } & STR & 3 & 3 & 1 & 7 \\
\hline & PR & 0 & 1 & 0 & 1 \\
\hline
\end{tabular}

Reope, reoperation; WHO, World Health Organization; GTR, gross total removal; STR, subtotal removal; PR, partial removal; SRS, stereotactic radiosurgery; SRT, stereotactic radiotherapy; IMRT, intensity modulated radiation therapy; 3D CRT, three dimensional conformal radiotherapy. \# The removal rate was categorized as GTR (Simpson grade I and II), subtotal removal (STR) (Simpson grade III), and partial removal (PR) (Simpson grade IV).

\subsection{OS and PFS}

A total of 9 patients died within the follow-up period. PFS rates at 2, 5, and 10 years after the first reoperation were $68.0 \%, 52.8 \%$, and $22.7 \%$, respectively (Figure 2). OS rates at 2, 5, and 10 years after the first reoperation were $94.3 \%, 86.4 \%$, and $71.7 \%$, respectively (Figure 2 ).

$\mathrm{PFS}$, after the first to second reoperation, was significantly longer than that after the second to third reoperation and from the third reoperation $(p=0.0053)$ (Figure $3 \mathrm{~A})$. The OS of the patients with one reoperation was significantly longer than that of the patients with two and three reoperations $(p=0.0005)$ (Figure 3B). The removal rate at the first reoperation was not associated with the longer PFS and OS (Figure 3C and 3D) ( $p=0.5918$ and $p=0.7160$, respectively).

A

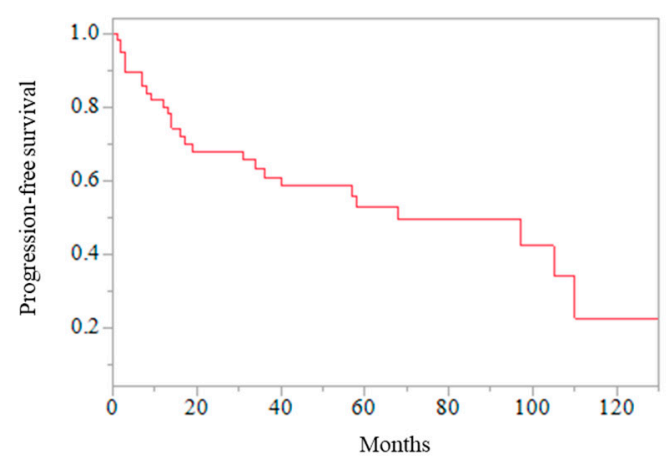

B

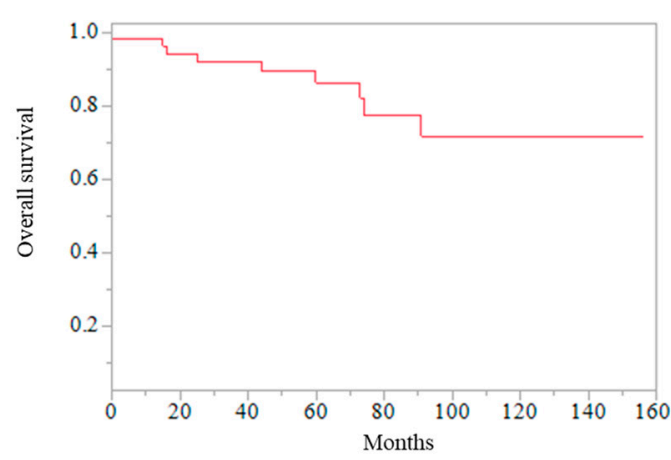

Figure 2. Kaplan-Meier curves of all the patients. (A) Progression-free survival after reoperation of skull base meningiomas. (B) Overall survival after reoperation of skull base meningiomas. 
A

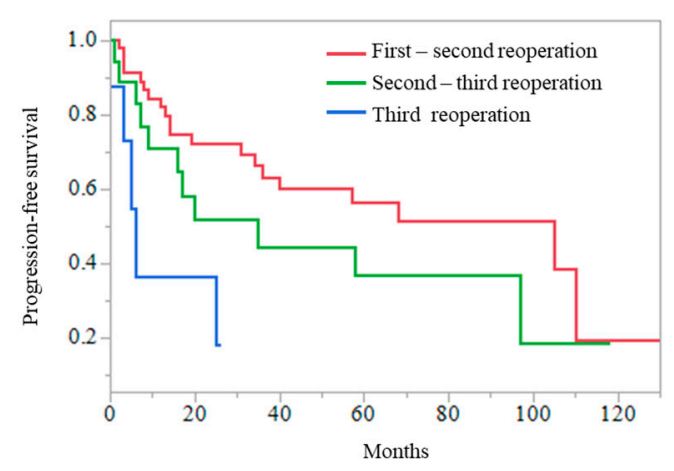

C

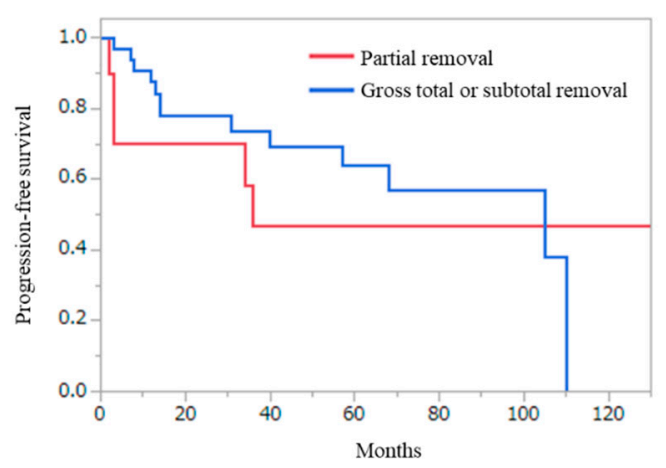

B

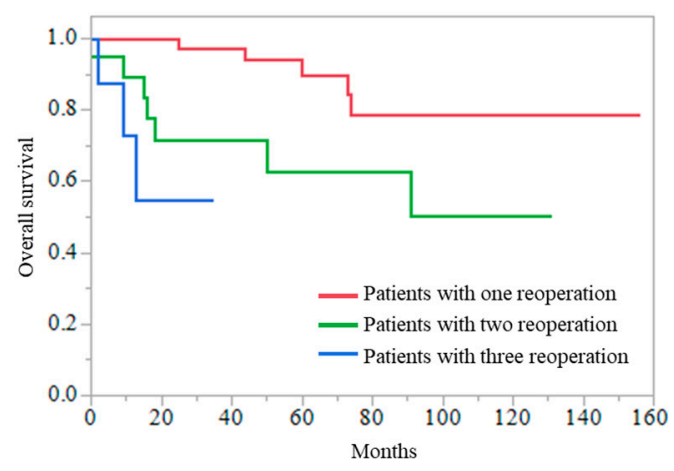

D

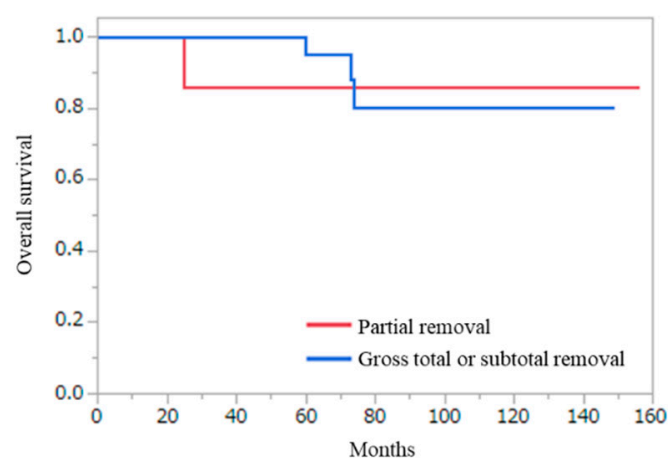

Figure 3. Kaplan-Meier curves, that are dependent on repeat reoperations and removal rate. (A) Progression-free survival from the first to second reoperation was significantly longer than that from the second to third reoperation and that from the third or later reoperations $(p=0.0053)$. (B) Overall survival of the patients with one recurrence was significantly longer than that of the patients with two and more than three recurrences $(p=0.0005)$. Progression-free survival $(\mathbf{C})$ and overall survival (D) from the first reoperation depending on the removal rate are shown.

The effect of adjuvant radiotherapy was also evaluated for recurrent SBMs (Figure 4). Radiotherapy did not improve PFS and OS for overall patients (Figure 4A and 4B) ( $p=0.8635$ and $p=0.4527$, respectively). In patients with WHO grade I SBMs, adjuvant radiotherapy did not improve the PFS and OS (Figure $4 \mathrm{C}$ and $4 \mathrm{D})(p=0.1233$, and $p=0.5685$, respectively). In contrast, in patients with WHO grade II SBMs, adjuvant radiotherapy significantly improved PFS (Figure 4E) $(p=0.0012)$. 
A

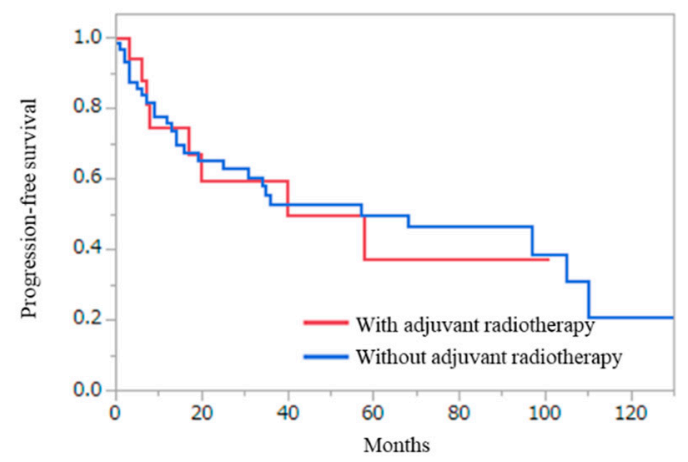

C

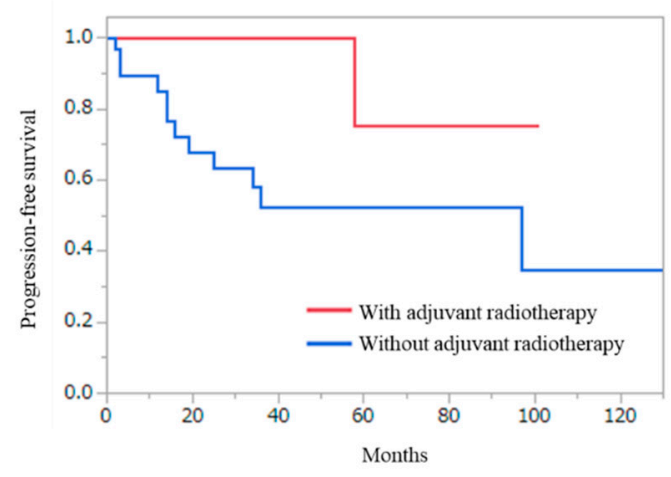

E

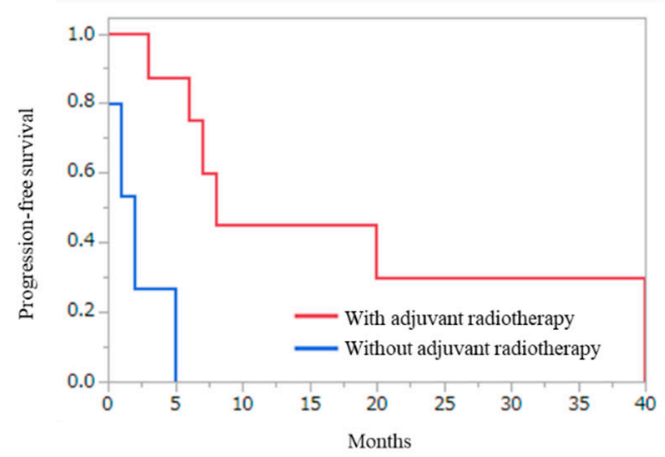

B

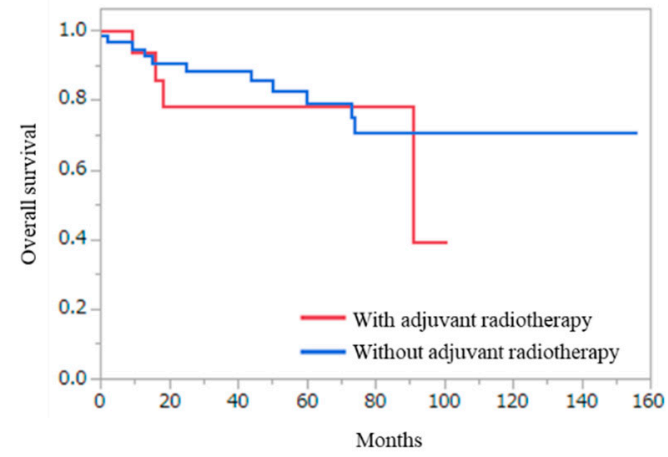

D

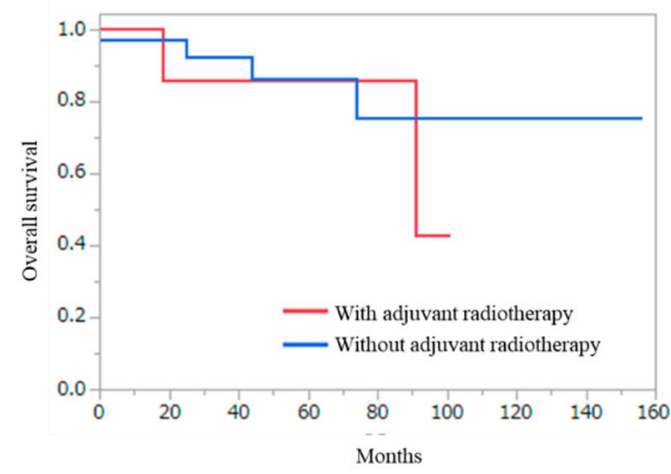

$\mathbf{F}$

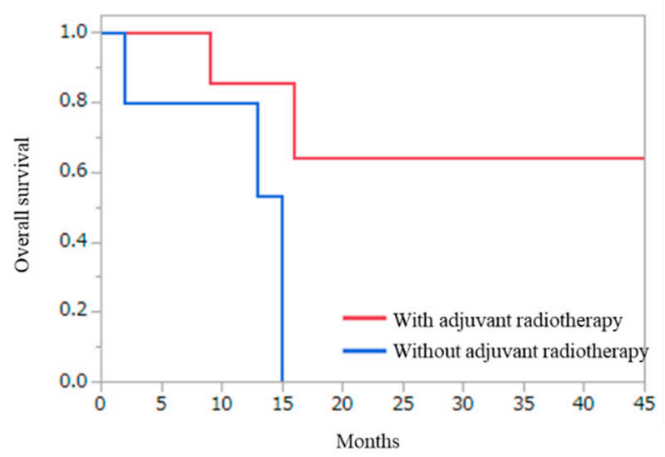

Figure 4. Kaplan-Meier curves of the patients depending on the adjuvant radiotherapy. Progression-free survival (A) and overall survival (B) of overall patients with recurrent skull base meningiomas. Progression-free survival (C) and overall survival (D) of the patients with subtotal and partial removal of WHO grade I skull base meningiomas. Progression-free survival (E) and overall survival (F) of the patients with subtotal and partial removal of WHO grade II skull base meningiomas. Adjuvant radiotherapy significantly improved PFS for patients with WHO grade II skull base meningiomas (Figure 4E) $(p=0.0012)$.

\subsection{Univariate and Multivariate Analyses}

To investigate the poor prognostic factors of recurrent SBMs after surgical resection, we performed univariate analysis with Cox regression models for the following variables: Age, sex, neurological progression (present versus not present), time since prior surgery ( $\geq 10$ years versus $<10$ years), tumor size ( $\geq 60 \mathrm{~mm}$ versus $<60 \mathrm{~mm}$ ), lesions (multiple versus single), WHO grade (II or III versus I), and removal rate (PR versus GTR or STR) (Table 6). Among these variables, WHO grading (II or III), lesions (multiple), and tumor size ( $\geq 60 \mathrm{~mm}$ ) were associated with shorter PFS and were included in the 
subsequent multivariate analysis (WHO grading, HR: 6.686, 95\% CI $=2.685-16.647, p<0.0001$; lesions, HR: 2.810, 95\% CI = 1.104-7.156, $p=0.030$; tumor size, HR: 2.203, 95\% CI $=0.756-4.759, p=0.173$ ).

Multivariate analysis was performed using WHO grading, lesions, and tumor size. The analysis showed that WHO grading (II or III) and lesions (multiple) were independent predictors of poor prognosis (WHO grading, HR: 7.031, 95\% CI = 2.739-18.050, $p<0.0001$; lesions, HR: $2.774,95 \%$ $\mathrm{CI}=1.049-7.336, p=0.040)$.

Table 6. Univariate and Multivariate Analysis.

\begin{tabular}{ccccccc}
\hline Variables & \multicolumn{3}{c}{ Univariate Analysis } & \multicolumn{3}{c}{ Multivariate Analysis } \\
\hline & HR & $\mathbf{( 9 5 \% ~ C I )}$ & $p$ Value & HR & (95\% CI) & $p$ Value \\
\hline Age & 1.004 & $(0.976-1.033)$ & 0.785 & & & \\
Sex (Female) & 1.486 & $(0.511-4.322)$ & 0.468 & & & \\
Neurological progression (Present) & 1.672 & $(0.750-3.731)$ & 0.209 & & & \\
Time since prior surgery ( $\geq 10$ years) & 0.562 & $(0.193-1.636)$ & 0.291 & & & \\
Tumor size ( $\geq 60$ mm) & 1.896 & $(0.756-4.759)$ & 0.173 & 2.203 & $(0.862-5.630)$ & 0.099 \\
Lesion (Multiple) & 2.810 & $(1.104-7.156)$ & 0.030 & 2.774 & $(1.049-7.336)$ & $\mathbf{0 . 0 4 0}$ \\
WHO grade (II or III) & 6.686 & $(2.685-16.647)$ & $<0.001$ & 7.031 & $(2.739-18.050)$ & $<0.0001$ \\
Removal rate (PR) & 0.984 & $(0.396-2.443)$ & 0.972 & & & \\
\hline
\end{tabular}

HR, hazard ratio; CI, confidence interval; WHO, World Health Organization; PR, partial removal. Boldface type indicate statistical significance.

\section{Discussion}

Several studies have described prognostic factors for primary meningiomas. In a study of 582 patients with primary meningiomas, Amey et al. demonstrated that skull base location, WHO grade II, and Simpson grade III-V resection were independent factors associated with unfavorable outcomes [8]. Similarly, removal rate and WHO grading were reported as prognostic factors for meningiomas in other reports using primary meningiomas [2,26].

Some studies have specifically investigated the difference in prognosis between SBMs and non-SBMs [1-3,8,27]. Although SBMs showed less invasive characteristics, such as lower MIB-1 index [1], the median time to recurrence was shorter in SBMs than in non-SBMs $[1,8,27]$. The difficulty of surgical treatment may be the cause of this discrepancy. GTR is difficult because SBMs are deep-seated and surrounded by critical vascular structures and cranial nerves [1,7,9-11]. Kira et al. [10] demonstrated that the proportion of patients with STR was higher in SBMs than in convexity and falx meningiomas, and the removal rate was the major prognostic factor for SBMs. Yu et al. [28] also recommended complete resection to achieve longer PFS on the basis of their clinical experience with 28 patients with atypical SBMs. Nanda et al. [29] demonstrated a significant association between the Simpson grading system and recurrence rates for both skull base meningiomas and convexity meningiomas. However, in the present study, although the removal rate (including Simpson grading scale) was reported as the strongest prognostic factor for primary meningiomas, it was not associated with shorter PFS of recurrent SBMs.

Although, the removal rate was reported to be associated with the prognosis of SBMs, aggressive removal must be carefully discussed. Aggressive removal was known to increase postoperative complications for SBMs. In the present study, new cranial nerve deficits and infections were the major complications for recurrent SBMs. The previous study demonstrated that the complication rate of recurrent SBMs is higher than that of other meningiomas [6].

In general, higher WHO grading has been associated with the poor prognosis of meningiomas [30]. According to a previous analysis of primary SBMs, 16 of 358 patients had WHO grade II meningiomas [10]. In SBMs, WHO grade II meningiomas were more common at the medial and lateral sphenoid ridge [1]. Atypical SBMs show poor clinical outcomes, but the literature regarding atypical SBMs is quite limited [28]. In the present study, most of the grade II meningiomas originated from the middle cranial fossa. We found that WHO grading was strongly associated with shorter PFS of recurrent SBMs. Although atypical and anaplastic meningiomas have been rarely observed 
in SBMs previously [4,5], atypical and anaplastic histological features have found to be important prognostic factors.

In other reports, tumor size, location, and bone- and venous sinus infiltration were reported as prognostic factors for SBMs $[19,31]$. Although these factors were not associated with the poor prognosis of recurrent SBMs, multiple lesions and/or dissemination were significant prognostic factors in the present study. In a previous study on disseminated meningiomas, tumor origins and WHO grading were not associated with dissemination [32]. The pathogenesis of leptomeningeal dissemination is still unknown.

In the recent decade, the efficacy of adjuvant radiotherapy has been demonstrated for high-grade meningiomas [15-17]. Hilary et al. demonstrated that adjuvant radiotherapy for meningiomas resected with Simpson grade I-III improved local control rates [16]. The prognosis of primary anaplastic meningiomas has been shown to be improved by adjuvant radiotherapy; however, in the subgroup analyses, no significant improvement was observed in either PFS or OS in patients with recurrent meningiomas [17]. In the present study, radiotherapy did not improve PFS and OS for overall patients. However, PFS of the patients with subtotal and partial removal for WHO grade II SBMs was significantly improved by the radiotherapy. Therefore, further development of the treatment strategy using radiotherapy is expected. For example, novel treatment strategies for recurrent SBMs, such as brachytherapy [33], may show treatment efficacy.

Although, it is difficult to completely establish a treatment strategy for recurrent SBMs, some diagnostic radiographical modalities may be useful [34,35]. Ching-Chung et al. [35] demonstrated that low apparent coefficient diffusion values were high-risk factors for the progression of SBMs.

The present study had some limitations. The main limitation was the small sample size, given that the prevalence of SBMs is relatively rare [1]. Further analysis with a larger sample size of patients with recurrent SBMs is required to confirm the findings of the present study.

\section{Conclusions}

To date, a few studies with a specific focus on recurrent SBMs have been reported. The present study demonstrated that WHO grading and multiple lesions were associated with shorter PFS of recurrent SBMs. PFS of patients with subtotal and partial removal for WHO grade II SBMs was significantly improved by the radiotherapy.

Author Contributions: Conceptualization, Y.K. and R.T.; methodology, Y.K. and R.T.; software, Y.K.; validation, N.T. and M.T.; formal analysis, Y.K.; resources, K.K. and Y.M.; data curation, R.T. and M.T.; writing-original draft preparation, Y.K.; writing - review and editing, R.T. and M.T.; supervision, K.Y.; project administration, M.T. All authors have read and agreed to the published version of the manuscript.

Funding: This research received no external funding.

Conflicts of Interest: The authors declare no conflict of interest.

\section{References}

1. Mansouri, A.; Klironomos, G.; Taslimi, S.; Kilian, A.; Gentili, F.; Khan, O.H.; Aldape, K.; Zadeh, G. Surgically resected skull base meningiomas demonstrate a divergent postoperative recurrence pattern compared with non-skull base meningiomas. J. Neurosurg. 2016, 125, 431-440. [CrossRef] [PubMed]

2. McGovern, S.L.; Aldape, K.D.; Munsell, M.F.; Mahajan, A.; DeMonte, F.; Woo, S.Y. A comparison of World Health Organization tumor grades at recurrence in patients with non-skull base and skull base meningiomas. J. Neurosurg. 2010, 112, 925-933. [CrossRef] [PubMed]

3. Hashimoto, N.; Rabo, C.S.; Okita, Y.; Kinoshita, M.; Kagawa, N.; Fujimoto, Y.; Morii, E.; Kishima, H.; Maruno, M.; Kato, A.; et al. Slower growth of skull base meningiomas compared with non-skull base meningiomas based on volumetric and biological studies. J. Neurosurg. 2012, 116, 574-580. [CrossRef] [PubMed] 
4. Cornelius, J.F.; Slotty, P.J.; Steiger, H.J.; Hanggi, D.; Polivka, M.; George, B. Malignant potential of skull base versus non-skull base meningiomas: Clinical series of 1,663 cases. Acta Neurochir. (Wien) 2013, 155, 407-413. [CrossRef]

5. Kane, A.J.; Sughrue, M.E.; Rutkowski, M.J.; Shangari, G.; Fang, S.; McDermott, M.W.; Berger, M.S.; Parsa, A.T. Anatomic location is a risk factor for atypical and malignant meningiomas. Cancer 2011, 117, 1272-1278. [CrossRef]

6. Magill, S.T.; Lee, D.S.; Yen, A.J.; Lucas, C.G.; Raleigh, D.R.; Aghi, M.K.; Theodosopoulos, P.V.; McDermott, M.W. Surgical outcomes after reoperation for recurrent skull base meningiomas. J. Neurosurg. 2018, 130, 876-883. [CrossRef]

7. Meling, T.R.; Da Broi, M.; Scheie, D.; Helseth, E. Skull base versus non-skull base meningioma surgery in the elderly. Neurosurg. Rev. 2018. [CrossRef]

8. Savardekar, A.R.; Patra, D.P.; Bir, S.; Thakur, J.D.; Mohammed, N.; Bollam, P.; Georgescu, M.M.; Nanda, A. Differential Tumor Progression Patterns in Skull Base Versus Non-Skull Base Meningiomas: A Critical Analysis from a Long-Term Follow-Up Study and Review of Literature. World Neurosurg. 2018, 112, e74-e83. [CrossRef]

9. Lemee, J.M.; Corniola, M.V.; Da Broi, M.; Joswig, H.; Scheie, D.; Schaller, K.; Helseth, E.; Meling, T.R. Extent of Resection in Meningioma: Predictive Factors and Clinical Implications. Sci. Rep. 2019, 9, 5944. [CrossRef]

10. Voss, K.M.; Spille, D.C.; Sauerland, C.; Suero Molina, E.; Brokinkel, C.; Paulus, W.; Stummer, W.; Holling, M.; Jeibmann, A.; Brokinkel, B. The Simpson grading in meningioma surgery: Does the tumor location influence the prognostic value? J. Neurooncol. 2017, 133, 641-651. [CrossRef]

11. Schneider, M.; Schuss, P.; Guresir, A.; Wach, J.; Hamed, M.; Vatter, H.; Guresir, E. Cranial Nerve Outcomes After Surgery for Frontal Skull Base Meningiomas: The Eternal Quest of the Maximum-Safe Resection with the Lowest Morbidity. World Neurosurg. 2019. [CrossRef] [PubMed]

12. Dasanu, C.A.; Samara, Y.; Codreanu, I.; Limonadi, F.M.; Hamid, O.; Alvarez-Argote, J. Systemic therapy for relapsed/refractory meningioma: Is there potential for antiangiogenic agents? J. Oncol. Pharm. Pract. 2019, 25, 638-647. [CrossRef] [PubMed]

13. Kaley, T.J.; Wen, P.; Schiff, D.; Ligon, K.; Haidar, S.; Karimi, S.; Lassman, A.B.; Nolan, C.P.; DeAngelis, L.M.; Gavrilovic, I.; et al. Phase II trial of sunitinib for recurrent and progressive atypical and anaplastic meningioma. Neuro. Oncol. 2015, 17, 116-121. [CrossRef] [PubMed]

14. Shih, K.C.; Chowdhary, S.; Rosenblatt, P.; Weir, A.B., 3rd; Shepard, G.C.; Williams, J.T.; Shastry, M.; Burris, H.A., 3rd; Hainsworth, J.D. A phase II trial of bevacizumab and everolimus as treatment for patients with refractory, progressive intracranial meningioma. J. Neurooncol. 2016, 129, 281-288. [CrossRef] [PubMed]

15. Wang, C.; Kaprealian, T.B.; Suh, J.H.; Kubicky, C.D.; Ciporen, J.N.; Chen, Y.; Jaboin, J.J. Overall survival benefit associated with adjuvant radiotherapy in WHO grade II meningioma. Neuro. Oncol. 2017, 19, 1263-1270. [CrossRef] [PubMed]

16. Bagshaw, H.P.; Burt, L.M.; Jensen, R.L.; Suneja, G.; Palmer, C.A.; Couldwell, W.T.; Shrieve, D.C. Adjuvant radiotherapy for atypical meningiomas. J. Neurosurg. 2017, 126, 1822-1828. [CrossRef] [PubMed]

17. Zhu, H.; Bi, W.L.; Aizer, A.; Hua, L.; Tian, M.; Den, J.; Tang, H.; Chen, H.; Wang, Y.; Mao, Y.; et al. Efficacy of adjuvant radiotherapy for atypical and anaplastic meningioma. Cancer Med. 2019, 8, 13-20. [CrossRef]

18. Faramand, A.; Kano, H.; Niranjan, A.; Park, K.J.; Flickinger, J.C.; Lunsford, L.D. Tumor Control and Cranial Nerve Outcomes After Adjuvant Radiosurgery for Low-Grade Skull Base Meningiomas. World Neurosurg. 2019, 127, e221-e229. [CrossRef]

19. Park, S.; Cha, Y.J.; Suh, S.H.; Lee, I.J.; Lee, K.S.; Hong, C.K.; Kim, J.W. Risk group-adapted adjuvant radiotherapy for WHO grade I and II skull base meningioma. J. Cancer Res. Clin. Oncol. 2019, 145, 1351-1360. [CrossRef]

20. DeMonte, F.; McDermott, M.W.; Al-Mefty, O. Al-Mefty's Meningiomas, 2nd ed.; Thieme Medical: New York, NY, USA, 2011.

21. Huang, R.Y.; Unadkat, P.; Bi, W.L.; George, E.; Preusser, M.; McCracken, J.D.; Keen, J.R.; Read, W.L.; Olson, J.J.; Seystahl, K.; et al. Response assessment of meningioma: 1D, 2D, and volumetric criteria for treatment response and tumor progression. Neuro. Oncol. 2019, 21, 234-241. [CrossRef]

22. Morimoto, Y.; Tamura, R.; Ohara, K.; Kosugi, K.; Oishi, Y.; Kuranari, Y.; Yoshida, K.; Toda, M. Prognostic significance of VEGF receptors expression on the tumor cells in skull base chordoma. J. Neurooncol. 2019, 144, 65-77. [CrossRef] [PubMed] 
23. Tsermoulas, G.; Turel, M.K.; Wilcox, J.T.; Shultz, D.; Farb, R.; Zadeh, G.; Bernstein, M. Management of multiple meningiomas. J. Neurosurg. 2018, 128, 1403-1409. [CrossRef] [PubMed]

24. Simpson, D. The recurrence of intracranial meningiomas after surgical treatment. J. Neurol. Neurosurg. Psychiatry. 1957, 20, 22-39. [CrossRef] [PubMed]

25. Tamura, R.; Tomio, R.; Mohammad, F.; Toda, M.; Yoshida, K. Analysis of various tracts of mastoid air cells related to CSF leak after the anterior transpetrosal approach. J. Neurosurg. 2018, 130, 360-367. [CrossRef]

26. Gallagher, M.J.; Jenkinson, M.D.; Brodbelt, A.R.; Mills, S.J.; Chavredakis, E. WHO grade 1 meningioma recurrence: Are location and Simpson grade still relevant? Clin. Neurol. Neurosurg. 2016, 141, 117-121. [CrossRef]

27. Meling, T.R.; Da Broi, M.; Scheie, D.; Helseth, E. Meningiomas: Skull base versus non-skull base. Neurosurg. Rev. 2019, 42, 163-173. [CrossRef]

28. Wang, Y.C.; Chuang, C.C.; Wei, K.C.; Hsu, Y.H.; Hsu, P.W.; Lee, S.T.; Wu, C.T.; Tseng, C.K.; Wang, C.C.; Chen, Y.L.; et al. Skull base atypical meningioma: Long term surgical outcome and prognostic factors. Clin. Neurol. Neurosurg. 2015, 128, 112-116. [CrossRef]

29. Nanda, A.; Bir, S.C.; Maiti, T.K.; Konar, S.K.; Missios, S.; Guthikonda, B. Relevance of Simpson grading system and recurrence-free survival after surgery for World Health Organization Grade I meningioma. J. Neurosurg. 2017, 126, 201-211. [CrossRef]

30. De Almeida, A.N.; Pereira, B.J.A.; Pires Aguiar, P.H.; Paiva, W.S.; Cabrera, H.N.; da Silva, C.C.; Teixeira, M.J.; Marie, S.K.N. Clinical Outcome, Tumor Recurrence, and Causes of Death: A Long-Term Follow-Up of Surgically Treated Meningiomas. World Neurosurg. 2017, 102, 139-143. [CrossRef]

31. Scheitzach, J.; Schebesch, K.M.; Brawanski, A.; Proescholdt, M.A. Skull base meningiomas: Neurological outcome after microsurgical resection. J. Neurooncol. 2014, 116, 381-386. [CrossRef]

32. Park, K.S.; Kim, K.H.; Park, S.H.; Hwang, J.H.; Lee, D.H. Intracranial meningioma with leptomeningeal dissemination : Retrospective study with review of the literature. J. Korean Neurosurg. Soc. 2015, 57, 258-265. [CrossRef] [PubMed]

33. Koch, M.J.; Agarwalla, P.K.; Royce, T.J.; Shih, H.A.; Oh, K.; Niemierko, A.; Mauceri, T.C.; Curry, W.T.; Barker, F.G.; Loeffler, J.S. Brachytherapy as an Adjuvant for Recurrent Atypical and Malignant Meningiomas. Neurosurgery 2019. [CrossRef] [PubMed]

34. Zhang, Y.; Chen, J.H.; Chen, T.Y.; Lim, S.W.; Wu, T.C.; Kuo, Y.T.; Ko, C.C.; Su, M.Y. Radiomics approach for prediction of recurrence in skull base meningiomas. Neuroradiology 2019. [CrossRef] [PubMed]

35. Ko, C.C.; Lim, S.W.; Chen, T.Y.; Chen, J.H.; Li, C.F.; Shiue, Y.L. Prediction of progression in skull base meningiomas: Additional benefits of apparent diffusion coefficient value. J. Neurooncol. 2018, 138, 63-71. [CrossRef] [PubMed]

(C) 2019 by the authors. Licensee MDPI, Basel, Switzerland. This article is an open access article distributed under the terms and conditions of the Creative Commons Attribution (CC BY) license (http://creativecommons.org/licenses/by/4.0/). 